between the intensity necessary for the perception of light and that for colour. Green, indeed, affords us the best clinical test of early failure of conduction, the appreciation of the colour failing, while that for light persists.

of these two sensations there is reascn to regard light perception as the more primitive, and the primitive type of visual cell is pigmented epithelium. We are encouraged, then, to consider this part of our retina as mainly concerned in the appreciation of light as distinguished from colour, and many facts support this view. Thus, in disease of the pigment epithelium there is difficulty in appreciating differences in the amount of light. Again, when changes have occurred in the pigment cells, when the eye is kept in the dark for about an hour, there is a remarkable increase in the sensitiveness of the retina to light. We may infer that the chemical action, induced by light on a particular secretion of the pigmented epithelium, is intimately associated with the causation of the effect recognised as light-sense; and the next step is to inquire how the impression is conveyed from the pigment cell, whether by rod- and conecells indifferently, or mainly by one of them. Although the power of appreciating a faint light stimulus is so markedly increased as a whole by " dark-adaptation," we find that this does not apply to the entire visual field, and does not apply equally to all parts of the field where it is increased. Thus in the central area the light-sense is actually diminished under these conditions; and whereas it is increased outside the central area, it is relatively more augmented as we approach the periphery. That is to say, it is not increased at all where cones alone are present, and the increase becomes more marked as the rods become more and more the predominant element. It has therefore been argued, with reason, that the rods are the elements concerned in the appreciation of light, or, rather, of the change produced in the pigment cells by light, while the eye is thus adapted; although whether or not the retinal purple is visually concerned may be considered still an open question. So definite is the physiological area of diminished lightsense in this condition that it can be shown to correspond with the projection of the rod-free foveal retina.

The only possible argument that can be adduced against this conclusion is the possibility that there may be a difference in the behaviour of the pigment cells them selves, in the central and peripheral regions of the fundus, but no evidence in favour of this has ever been brought forward. Granted, then, that the rods have this particular function, it by no means follows that the cones are not serviceable in the appreciation of light in ordinary illumination, though their peculiar office is presumably concerned with the recognition of differences of stimulation associated with variations in wave-length reoognised as colours. Indeed, we know that light is ordinarily appreciated with marked efficiency by the macular area, but it is possibly always in virtue of the same function that is concerned in colour vision, white light being recognised, not as a simple result of stimulation, but as a consequence of, say, three simultaneous stimuli any one of which alone would excite a central impression of colour. It would seem as if a minor amonnt of stimulation that can be appreciated only by the rods must be excited before the cones come into functional activity. It is possible that the first action of light on the pigment cell is instrumental in providing a product of secretion or decomposition that is required so that the finer differences in wave-lengths be appreciated by the cones and the colour-sense stimuli be thereby initiated. Very possibly the movement of the conemoid is of service in this association.

PURE ButTRr.-Recently a firm of grocers at Rhyl sued a Liverpool firm of butter merchants for costs sustained in defending an action in which they were charged with selling butter adulterated with boric acid. Judge Lloyd decided in favour of the plaintiffs on the ground that butter containing boric acid was not absolutely pure. The case was then taken to the High Court and remitted back to Judge Lloyd for consideration as to whether it was pure butter according to the trade. At the Rhyl County Court on June $22 n d$ it was stated that the plaintiffs had consented to a judgment for defendants and agreed to pay £15 costs. His Honour consented to the settlement, but remarked that although butter which contained boric acid as a preservative might be regarded as pure in the trade, it could not be absolutely pure according to the customers' idea.

\section{UNUSUAL COMPLICATION FOLLOWING GASTRO-JEJUNOSTOMY. ${ }^{1}$}

BY W. H. BROWN, F.R.C.S. IREL.,

SURGEON TO THE LEEDS GENERAI INFIRMARY.

I RELATE the following case to offer another instance of a good result following operative interference when there seemed to be but a forlorn hope of giving relief.

The patient, a woman, aged 62 years, had suffered for many months from pain after food, the pain gradually becoming most acute so that opium in full doses was needed to obtain anything like comfort. Latterly regular attacks of vomiting occurred about every 48 hours, when most of the nourishment taken during the preceding two days returned. No tumour could be felt but the symptoms all pointed towards pyloric stenosis. As the condition of the patient was getting unendurable I decided, after consultation with Dr. T. Churton, to open the abdomen to see if anything could be done. At the operation I found the pylorus greatly thickened and masses of enlarged glands constituting too great an area of disease to be attacked with any degree of safety. I therefore joined up a loop of jejunum to the stomach, using Senn's plates as the scaffold of anastomosis.

For the next two weeks all went as well as such cases usually do; the vomiting ceased and the pain gradually subsided. At the end of that time, however, the symptoms of obstruction began to reassert themselves, the pain again grew severe, and again the regular vomiting began, the amount corresponding with the quantity of fluids taken. It seemed clear that the new opening had for some reason or other ceased to be effectual. I therefore was face to face with a most discouraging chain of events and the patient herself was as badly off as she was before she submitted herself to operative interference. I decided to act on the assumption that the new opening between the stomach and the jejunum had closed and determined to re-open for the purpose of ascertaining the reason. Accordingly I re-opened the abdomen and I found that the junction between the bowel and the stomach externally was quite satisfactory. I then made an incision into the stomach two inches above the junction, and putting my finger inside found that all trace of the bone-plate had disappeared and also that all trace of the opening was absent. After a minute or two I felt the edge of the oval cut of the former operation and pressing firmly in the centre of this tore through a membrane by which the opening had been occluded. My finger then passed easily into the bowel and I stretched the opening freely in all directions. I then closed the exploratory incision into the stomach and finished the operation in the usual manner. After a day or two, during which time vomiting was inces. sant, improvement set in. The pain again left and it has not since returned. The patient is able to take light food and the vomiting has ceased. She is now ont of bed daily and is gaining strength.

I have had occasion to operate for the relief of pyloric stenosis a good many times and in each instance I have used Senn's plates, but never before has the disaster I have related taken place. The membrane through which I tore was about as thick as ordinary note-paper. I do not know what occasioned the formation.

I said at the commencement of the notes of this case that I related it to add to the number of recorded surgical successes under desperate circumstances. With the condition which I have related to hold one's hand was to let the patient die in great distress; to operate again gave her one chance, but it also exposed her to the risk of death upon the operating table. Problems such as these come before us only too frequently and end only too often disastrously. I think it right, therefore, to put upon record this case, as it may possibly afford a guide as to the line of action to be decided upon should failure to relieve attend upon operation for a like con. dition.

June 24th.-The patient is now well, taking ordinary food and doing her ordinary work.

Leeds.

1 A paper read before the Leeds and West Riding Medico-Chirurgical Society on May 4th, 1900. 